NASA Technical Memorandum 106599

AIAA-94-3163

$$
1247=
$$

\title{
Fuzzy Logic Approaches to Multi-Objective Decision-Making in Aerospace Applications
}

Terry L. Hardy

Lewis Research Center

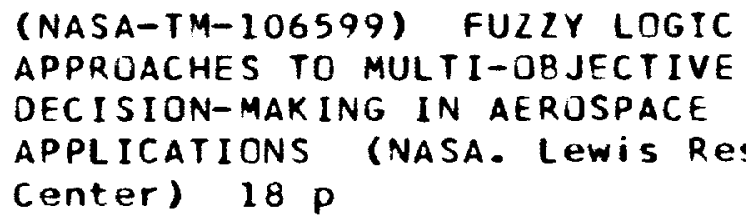

Cleveland, Ohio

Prepared for the

30th Joint Propulsion Conference

sponsored by the American Institute of Aeronautics and Astronautics

Colorado Springs, Colorado, June 20-23,1994

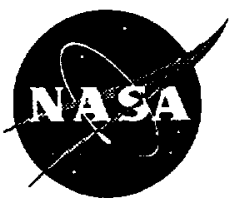

National Aeronautics and

Space Administration 


\title{
FUZZY LOGIC APPROACHES TO MULTI-OBJECTIVE \\ DECISION-MAKING IN AEROSPACE APPLICATIONS
}

\author{
Terry L. Hardy \\ National Aeronautics and Space Administration \\ Lewis Research Center \\ Cleveland, Ohio 44135
}

\begin{abstract}
Fuzzy logic allows for the quantitative representation of multi-objective decision-making problems which have vague or fuzzy objectives and parameters. As such, fuzzy logic approaches are well-suited to situations where alternatives must be assessed by using criteria that are subjective and of unequal importance. This paper presents an overview of fuzzy logic and provides sample applications from the aerospace industry. Applications include an evaluation of vendor proposals, an analysis of future space vehicle options, and the selection of a future space propulsion system. On the basis of the results provided in this study, fuzzy logic provides a unique perspective on the decision-making process, allowing the evaluator to assess the degree to which each option meets the evaluation criteria. Future decision-making should take full advantage of fuzzy logic methods to complement existing approaches in the selection of alternatives.

Nomenclature

$\begin{array}{ll}\text { A/R } & \text { Air-breathing/Rocket } \\ \text { BV } & \text { Best value of a criterion } \\ \text { H2 } & \text { Hydrogen } \\ \mathrm{I}_{\text {sp }} & \text { Specific impulse, sec } \\ \mathrm{L} & \text { Second-level index value } \\ \mathrm{L}_{\mathrm{h}} & \text { Final composite index value } \\ \mathrm{L}_{\max } & \text { Maximum of final composite index values } \\ \mathrm{L}_{\min } & \text { Minimum of final composite index values } \\ \text { LOX/CH4 } & \text { Liquid oxygen/methane } \\ \text { LOX/LH2 } & \text { Liquid oxygen/liquid hydrogen } \\ \text { NTO/MMH } & \text { Nitrogen tetroxide/monomethyl hydrazine } \\ \text { O2 } & \text { Oxygen } \\ \text { p } & \text { Balancing factor } \\ \text { QFD } & \text { Quality Function Deployment }\end{array}$
\end{abstract}

Rocket-based combined cycle

First-level index value

SSTO Single-stage-to-orbit

STS Space Transportation System

TSTO Two-stage-to-orbit

$\mathrm{U}$ Total utility value

$\mathrm{U}_{\mathrm{L}} \quad$ Left utility value

$\mathrm{U}_{\mathrm{R}} \quad$ Right utility value

w Weighting factor

WV Worst value of a criterion

Z Evaluation criterion actual value

$\mu_{\mathrm{G}} \quad$ Minimizing set

$\mu_{M} \quad$ Maximizing set

\section{Introduction}

Often in aerospace applications engineers and managers are asked to make decisions on the basis of widely divergent objectives. For instance, contract proposals may be evaluated on the basis of technical merit, total cost, ability to meet schedule requirements, and intangible attributes such as previous performance. In such situations experts are asked to evaluate the proposals on the basis of their best judgement. Often, only qualitative or vague statements can be made, such as good performance, or poor cost. Experts then apply numerical ratings to these vague, or fuzzy, terms to assist in the evaluation. However, each of the scoring criteria may have a different degree of importance depending on the approach of the evaluation. This relative importance must be taken into account to assure that the best decision is made among many different alternatives.

Fuzzy logic provides a means for evaluating alternatives where the objectives and criteria are vague and where the ranking criteria themselves vary in importance. Fuzzy logic is a subset of conventional logic that 
has been extended to allow for degrees of truth - truth values between true and false. Fuzzy logic has been used in a variety of applications, including control systems, ${ }^{1,2}$ artificial intelligence,,$^{3,4}$ and reliability analyses. ${ }^{5,6}$ Fuzzy logic approaches have also been used in civil engineering applications for assisting in the selection of disposal sites for hazardous waste, ${ }^{7.8}$ management of multipurpose aquifers ${ }^{9}$ and selection of site locations for dredged material. ${ }^{10}$

This report will show how methods provided in the literature can be applied to decision-making in aerospace applications. The report will provide a background on fuzzy logic, including a description of the differences between classical set theory and fuzzy set theory. Three examples will be used to illustrate how fuzzy logic can be used in the aerospace industry. These examples will be a hypothetical bid proposal evaluation, selection among various space vehicle candidates for Earth-to-Orbit transportation, and a space propulsion system selection process. The differences between conventional and fuzzy logic approaches to multi-objective decision-making will be discussed in the presentation of the examples.

\section{Fuzzy Logic}

Fuzzy logic is not itself logic which is fuzzy, but rather it is a rigorous mathematical discipline for examining complex systems where the objectives and controlling parameters are vague or qualitative in nature. To understand fuzzy logic one must first examine classical mathematics. Classical set theory, the basis for most decisionmaking processes, allows for two options: either something is a member of a set or it is not a member. An example of a classical or crisp set would be the set of mammals. In this set a dog would be a member of the set whereas an eagle is not. Difficulties arise, however, when the platypus is considered in the set of mammals. The platypus lays eggs and has a duck-like bill, yet is warmblooded and is covered with fur. Classical set theory says the platypus must either be a member of the set of mammals or not a member. In fact, the platypus is somewhat a mammal and somewhat not a mammal, so it is a partial member of this set. ${ }^{3}$

Fuzzy logic, based on fuzzy set theory, accommodates such situations through the concept of partial membership. In fuzzy set theory, developed by Lotfi Zadeh in $1965,{ }^{11}$ everything is a matter of degree. Therefore, the platypus could be assigned a value indicating how much it is a member of the set of mammals. In addition, fuzzy logic allows for a gradual transition between not being a member of the set and being a full member of the set. Consider the example of the set of old people, where old is a vague term. One might say, according to crisp set theory, that 60 is the dividing point between old and not-old. Therefore, people over this age are old and those less than 60 are young. In a fuzzy set, however, someone 55 years of age might be assigned a value of 0.6 to the set of old people, meaning that they are somewhat old. A 90 -year-old person, on the other hand, would be considered very old, and hence be assigned a value of 1 for their degree of membership in the set. Figure 1 graphically depicts this example.

The concepts of partial membership and gradual transition between membership and nonmembership are intuitive when one observes real world situations. However, when mathematical models are developed, analysts usually make assumptions forcing a black or white view of the world due to limits of conventional logic. Fuzzy logic allows for a break from that view, allowing for partial truth, or gray areas. Uses of fuzzy logic begin to become evident in engineering systems as each application is examined. For instance, in reliability analyses it is clear that not all failures cause complete system loss. There may be failures and degradations in the system of varying degrees. In another example, humans can exhibit behavior in power plant operation that can drastically affect the system performance in unpredictable ways. That behavior can be expressed in vague or qualitative terms, but the behavior is inherently difficult to quantify. Fuzzy logic can be applied to address vagueness in these and many more applications. This is contrasted with probability theory, which is commonly used to treat imprecision. Probability theory rests on the concept that imprecision is the result of randomness. However, in many applications, such as those discussed above, imprecision is not the result of randomness alone. Hence, fuzzy logic becomes necessary to evaluate systems in which the description is vague, qualitative, or subjective.

The concept of partial membership makes fuzzy logic ideal for application to a multi-objective decisionmaking process. In such a process the decision maker is presented with a number of alternatives and is asked to choose the best option. Usually the choice is not simply made on the basis of a single objective. For instance, when a person seeks to purchase a new automobile, that person may desire low cost; however, size, safety, comfort, and reliability may all be important factors entering into the final decision. Ultimately, the potential buyer mentally ranks the importance of each criterion and makes a decision on the basis of those priorities. Fuzzy logic provides a method for quantifying such trade-offs, even if some of these factors (such as comfort in this example) are vague, subjective, or qualitative in nature.

\section{Sample Applications}

Three examples are presented to illustrate the fuzzy logic evaluation techniques. In the first example, 
hypothetical proposals from several vendors are considered for a technical contract. In the second example, options for future space vehicles for Earth-to-Orbit transportation applications are evaluated. Finally, alternatives are examined for future upper stage propulsion systems.

\section{BroposalEvaluation}

One of the most common situations where a subjective rating process is applied is in the evaluation of vendor proposals for a technical contract. In the selection process experts are asked to perform an evaluation on the basis of factors such as technical performance and cost. In most cases quantitative values are applied to qualitative and subjective (fuzzy) rating criteria to obtain a final ranking of the alternatives. Commonly, relative weights are applied to each criteria and the final vendor rating is obtained by adding the sum of the weighted ratings for each criteria. For instance, if a vendor is perceived to have a very good technical proposal, but the cost is high, the evaluator may assign a value of 0.7 for the technical portion and a 0.3 for the cost portion of the proposal. If cost is twice as important as the technical performance in the eyes of the evaluator, the final rating for that proposal would be $(0.70)(0.33)+(0.30)(0.67)=0.43$.

Consider as an example that a request for proposals was issued for technology development; such a case might occur in the development of a new rocket engine. Assume that four proposals were received to build the new rocket engine. The proposing vendors will be designated as A, B, C, and D. The evaluation will be conducted on the basis of technical and cost considerations, and the technical aspect of the proposal will consist of five factors. The evaluation criteria and relative weights for each of the criteria are described as follows:

Technical Item 1 - Understanding the problem

Technical Item 2 - Soundness of approach

Technical Item 3 - Organization of technical effort

$10 \%$

Technical Item 4 - Special equipment/facilities

$5 \%$

Technical Item 5 - Specific company capabilities

$5 \%$

Cost

Each proposal will be evaluated on a scale of 0 to 1 for each of these six areas. A rating of 1 implies that the particular portion of the proposal is outstanding whereas a rating of 0 implies that the proposal is unacceptable in a particular area. Intermediate scores are used to describe evaluations between these extremes. For instance, one option may have a low cost, which is very good, and would receive a score of 0.7 , whereas another would have a reasonable high cost, which is fair, and would receive a score of 0.3 . The adjective ratings and associated scores can be summarized as follows:

$\begin{array}{cc}\text { Outstanding } & 1.0 \\ \text { Excellent } & 0.9 \\ \text { Very Good } & 0.7 \\ \text { Good } & 0.5 \\ \text { Fair } & 0.3 \\ \text { Poor } & 0.1 \\ \text { Unacceptable } & 0.0\end{array}$

Assume that an evaluator rates the four proposals as shown in Table 1 . The evaluator can now rank the proposals by using conventional approaches and the raw scores. Weighting factors were obtained from the previously determined criteria. The raw scores are multiplied by the weight for each criteria, and a total score for each alternative is obtained by summing the weighted scores. Table II shows the results for this example. In this case Vendor B showed the highest score, followed by Vendor $C$ then Vendor D. Vendor B's high ratings in the technical areas led to the selection as the option of choice in this case.

The proposal evaluation can also be conducted by using fuzzy logic techniques. In the fuzzy logic method, described in detail in references 7,8 , and 12 , the evaluator first rates each vendor against the desired criteria on a scale of 0 to 1 , where a score of 1 indicates "goodness," as discussed in the conventional process. These scores are referred to as the raw scores. After all the options have been rated, a paired-attribute matrix is prepared to rank the importance of each criterion against all the other criteria. By calculating the eigenvectors of the maximum eigenvalues of this matrix the relative weighting factor of each of the criteria can be obtained. The raw scores are then raised to the power of the weighting factor to give the weighted ratings. These weighted ratings show the degree to which each vendor meets each criteria. According to fuzzy set theory, ${ }^{12}$ when a decision is made on a number of fuzzy criteria where all criteria are important, the intersection of the sets is required. In mathematical terms, the minimum value of all weighted attribute scores must be used to obtain the final ranking of a option. Then, the best option is the largest of these minimum scores.

The fuzzy logic process can be performed by using the raw scores in Table 1. Following compilation of the raw scores, a matrix was produced showing the relative importance of each of the criteria in comparison to 
the other criteria. This was done by taking the relative weights used in the conventional analysis and dividing each weight by the value assigned to each of the criteria. When this was completed for all attributes, the final result was a square matrix with a value of 1 along the diagonal. The paired attribute matrix for this example is shown in Table 3. Note that other methods, such as the Analytic Hierarchy Process, exist for obtaining this paired attribute matrix, as described in reference 10 . The fuzzy logic weighting factors were obtained from the matrix as discussed previously, and the alternatives were then ranked by using the minimum weighted score.

The fuzzy logic weighted rankings for this example are provided in Table 4. As seen in the table, the alternative of choice from the fuzzy logic procedure is Vendor C, not Vendor B as was found in the conventional analysis. This result makes sense in that the cost had the highest importance in comparison to the individual technical alternatives. The results of the analysis lead to the conclusion that as long as a vendor can meet some minimum for the technical requirements, the evaluator should choose the option with the lowest cost. This was not clear from the conventional analysis, which put more emphasis on the high technical scores even though these criteria may not have been as important to the evaluator. Therefore, without some method such as the fuzzy logic technique shown here, a decision can be made on the basis of the least important factors. As shown by the example, fuzzy logic techniques emphasize the most important factors in an evaluation and allow the evaluator to decide among alternatives on this basis.

Space Vehicle Candidate Evaluation for Earth to Orbit Transportation

It is evident from today's space market that many commercial and exploration missions are not being implemented due to the high cost of transportation to space. Therefore, NASA must explore options to reduce the costs of space access. Recently, NASA completed the Access to Space study to define a national strategy to meet future space transportation needs. ${ }^{13}$ Three options were examined for the Access to Space study. Option 1 was to improve the existing Space Transportation System. Option 2 was to develop a new family of expendable launch vehicles and a manned vehicle. Option 3 was to develop a new fully reusable launch vehicle.

Concurrent with this activity, the Space Propulsion Synergy Group bas been evaluating competing space propulsion options for improved access to space. The Space Propulsion Synergy Group is a national organization of personnel from the aerospace industry, academia, NASA Centers, and other government agencies formed in 1991 to support strategic planning for Earth-to-Orbit space transportation and propulsion systems. ${ }^{14,15}$ The Synergy Group recently completed a study of propulsion system options by using the Quality Function Deployment (QFD) process. The QFD process is a method for clarifying and documenting customer concerns so that critical attributes can be identified, prioritized, and translated into intelligent decisions. ${ }^{14}$ From this study 23 desired system attributes were identified. By using these system attributes and the knowledge gained as part of their previous study, the Synergy Group analyzed the proposed vehicle candidates from the Access to Space study to prioritize the options. ${ }^{16}$ The propulsion options considered are listed in Table 5.

In this analysis the Synergy Group rated each vehicle candidate against the attributes and assigned a discrete score of $0,1,3$, or 9 , with a higher score indicating goodness. The desired system attributes were then rated against each other to determine their relative importance, as in the previous example. A weighting factor was determined on the basis of the attribute ranking. The weighting factor was multiplied by the attribute score for each option, and the sum of the weighted rankings was used to determine a total score for each option. The results of this analysis are shown in Table 6.

In the current study this procedure was repeated by using the top nine attributes, rated by the weighting factor, in order to produce a manageable number of attribute scores. The results of this analysis are shown in Table 7. As seen in the table, there was no difference in the order of selection when the top nine attributes were used instead of twenty-three. Following this calculation the optimum propulsion system was determined by using fuzzy logic methods. For the fuzzy logic study the Synergy Group ratings, which were on a scale of 0 to 9 , were used and divided by 10 to allow them to fall in the range required by fuzzy set theory. Then, a matrix was prepared to rate the attributes against each other. This matrix was developed from the Synergy Group weighting factors. The fuzzy logic weighting factors were then calculated as described in the previous example. The final weighted results were obtained by raising the raw scores to the power of the fuzzy logic weighting factor.

Table 8 shows the results from the fuzzy logic analysis based on the Space Propulsion Synergy Group results. From the analysis the top two options remain the same as those found in previous analyses: the SSTO O2/ H2 (Single-Stage-To-Orbit, Oxygen/Hydrogen) Rocket and the SSTO RBCC (Rocket-Based Combined Cycle) options had the highest scores. However, the order of the other options showed some significant differences. The Conventional Expendable system moved from being the sixth-best option to third-best, tied with the TSTO A/R Fully Reusable (Two-Stage-To-Orbit, Air/Rocket) option. 
The SSTO Dual Fuel option fell from fourth to fifth place, and the SSTO Slush H2 RBCC fell from fifth to sixth, tied with Conventional Partially Reusable options. The upgrades to the existing expendable and existing reusable vehicles remained as the lowest rated options.

One reason for the change in the order of selection is related to the significance of the "Easily Supportable" criterion. Because supportability was defined by the Synergy Group as a critical element in the decision process, the fuzzy logic results emphasized this criterion. Therefore, the low scores for the TSTO and the SSTO Slush H2 RBCC in this category led to reduced rankings for these vehicles. In addition, the SSTO Dual Fuel concept fell in rank due to a low rating in the "Capacity" criterion. In the raw scoring this option received one high score in the "Easy Vehicle Integration" attribute. This one high score played a key role in the higher score for this vehicle in comparison to the Conventional Expendable option in the original study. However, the fuzzy logic results were based on the attributes for which the SSTO Dual Fuel concept was not well-suited, such as the capacity. Therefore, the fuzzy logic result was not influenced by the high score for the vehicle integration attribute.

Although the fuzzy logic results did not show differences in the best-scoring options, the method warrants consideration for future decision-making processes. By using the minimum value of the weighted scores, the fuzzy logic method focuses on the degree to which each objective is met by the alternatives. The goal of the process is to find the best option assuming all the options are important. Therefore, by using the minimum value of the weighted scores may allow for a different perspective on the decision process. By doing an arithmetic weighting as was done in the original Synergy Group study, the high scores can dominate the results. While focusing on those attributes that are good for each option is important, it is equally important to evaluate which attribute may hinder development at a later time. Therefore, it is suggested that the future propulsion decision-making, including those incorporating QFD approaches, take advantage of recent work in fuzzy logic as a complement to arithmetic weighting to assist in the selection process.

\section{Space Propulsion Candidate Evaluation for Upper Stage Application}

In the previous examples the assessments of alternatives were performed on the basis of evaluation input that was crisp (single values were used) but subjective. Often, however, trade-offs are required when the evaluation criteria have a large degree of uncertainty. In this case the criteria may be presented as a range of possible values instead of crisp values. For instance, in purchasing an automobile the buyer may not know the exact price of the vehicle, but may know what the price range will be. Under these conditions the selection process may become difficult as the ranges between automobile options may overlap. Recently, fuzzy logic has been used to make decisions where the input is uncertain. ${ }^{10,17}$ The following example, which uses methods from references 10 and 16 , illustrates this use of fuzzy logic.

The propulsion system used for orbit transfer in space is often referred to as the upper stage, and typically has a thrust level of 10,000 to $50,000 \mathrm{lb}_{\mathrm{f}}$. A propulsion system of this size also would have application for interplanetary flight, or for transfer to and from the lunar surface. ${ }^{18}$ In considering future propulsion systems, the options are usually distinguished by the propellants used. Each propulsion system must be evaluated on the basis of a number of factors, such as cost, reliability, and performance. Assume that three options are being considered for a future upper stage system: a liquid oxygen/liquid hydrogen system (LOX/LH2), a nitrogen tetroxide/ monomethyl hydrazine system (NTO/MMH), and a liquid oxygen/methane system (LOX/CH4). These systems are to be compared on the basis of cost and three technical criteria: specific impulse $\left(\mathrm{I}_{\mathrm{sp}}\right)$, weight, and reliability. The evaluation is to be conducted assuming that the reliability is twice as important to the evaluators as the specific impulse, and four times as important as the weight. The cost is 1.5 times as important as the technical criteria in this evaluation. In addition, the evaluation criteria are only known approximately because the propulsion systems have not yet been built. However, ranges of these parameters are known in terms of most likely values and largest likely values on the basis of past experience and expert opinion. These values are given in Table 9.

Methods for solving evaluations such as these are provided in references 10 and 17 . The first step in the evaluation is to group the criteria such that they reduce to a single criterion. This grouping is shown in Fig. 2 . The set of basic criteria are known as the first-level criteria, and include $\mathrm{I}_{s p}$,weight, reliability, and cost. The secondlevel criteria are technical and cost criteria, and the final composite criterion is the system.

The next step in the process is the construction of trapezoidal fuzzy sets to represent the uncertainty in the basic criteria. Figure 3 shows an example of such a fuzzy set. In the figure the most likely values for a particular criteria are assigned a value of 1 for the membership function, which is a measure of the degree of membership. The largest likely values are assigned a value of 0 for the membership function. The membership function is assumed to be linear for values between the most likely and largest likely values, thus providing the trapezoidal shape. The third step in determining the optimum alternative is to transform the fuzzy sets for each first-level crite- 
rion into an index value. This first-level index value normalizes the fuzzy sets in relation to the best and worst values for a particular criterion. As shown in reference 10 , the index value, $S$, can be calculated for each criterion, $\mathrm{Z}$, as follows:

If Best Value (BV) > Worst Value (WV):

$$
\begin{array}{ll}
\mathrm{S}=1 & (\mathrm{Z}>\mathrm{BV}) \\
\mathrm{S}=(\mathrm{Z}-\mathrm{WV}) /(\mathrm{BV}-\mathrm{WV}) & (\mathrm{WV}<\mathrm{Z}<\mathrm{BV}) \\
\mathrm{S}=0 & (\mathrm{Z}<\mathrm{WV})
\end{array}
$$

If Best Value (BV) < Worst Value (WV):

$$
\begin{array}{ll}
S=1 & (\mathrm{Z}<\mathrm{BV}) \\
\mathrm{S}=(\mathrm{Z}-\mathrm{WV}) /(\mathrm{BV}-\mathrm{WV}) & (\mathrm{BV}<\mathrm{Z}<\mathrm{WV}) \\
\mathrm{S}=0 & (\mathrm{Z}>\mathrm{WV})
\end{array}
$$

For example, if the criterion is cost or weight, then lower values are better, and the best value is less than the worst value. If the criterion is specific impulse or reliability, then higher values are better, and the best value is greater than the worst value. Because there are four values assigned to the fuzzy set, corresponding to the most likely and largest likely values, there will be four values of the index value. The best and worst values used in this example are provided in Table 10. Figure 4 illustrates the firstlevel index values for the NTOMMM system cost as an example. In this case the first-level index values are 0.7 , $0.6,0.4$, and 0.3 corresponding to the raw values $1.5,2.0$, 3.0 , and 3.5 million dollars, respectively.

Next, the second-level index values, $L$, are calculated by using weighting factors, $w$, and balancing factors, $p$, as follows:

$$
L=\left(\sum_{i} w_{i} S_{i} p\right)^{\frac{1}{\bar{p}}}
$$

The weighting factors, which are used to indicate the relative importance of each criterion, are determined in a method similar to that discussed in previous examples. A paired attribute matrix is prepared by using the relative importance of each criterion. In this case two matrices will be developed: one for the technical criteria of specific impulse, weight and reliability to obtain the technical index, and another for the comparison between technical and cost to obtain the final composite index. The eigenvectors of the maximum eigenvalues are then calculated as before. The weighting factors are obtained by normalizing the eigenvectors such that all the weighting factors for each comparison sum to a value of 1 . The weighting factors are provided in Table 11. The balancing factors are used to reflect the maximum deviation or difference between a criterion value and the best value for that criterion. The larger the value of the balancing factor, the greater the concern with respect to that criterion's deviation. As described in reference 16, a value of 1 or 2 appears to be a good choice for $p$. In this example the balancing factor was assumed to be 1 in all cases. As in the case of the first-level index, four values of the secondlevel index will result for the cost and for the technical criteria.

As an illustrative example of the second-level index value, consider the technical criteria for the LOXJ LH2 system. Values of $0.86,0.30$, and 0.96 were obtained for one of the first-level index values for $I_{s p}$, weight, and reliability, respectively. By using the weighting factors from table XI this second-level index value as:

$$
\begin{aligned}
& L=((0.354)(0.86)+(0.177)(0.30)+(0.467)(0.96))^{1} \\
& L=0.806
\end{aligned}
$$

The final composite index values, $L_{h}$, can be obtained as follows:

$$
L_{h}=\left\{w_{\text {technical }} L_{\text {technical }}+w_{\cos t} L_{\cos t}\right\}^{\frac{1}{p}}
$$

The four composite index values for each alternative correspond to a fuzzy set. The resulting fuzzy sets for the alternatives in this example are provided in Fig. 5. As seen by the figure, the fuzzy sets show significant overlap; therefore, a method is required to rank the alternatives.

To rank the options, the maximizing and minimizing set concepts of fuzzy logic are used. This ranking method is illustrated in Fig. 6 . The maximizing set, $\mu_{M}$, is defined as:

$$
\begin{array}{ll}
\mu_{M}=\left(L_{h}-L_{\min }\right) /\left(L_{\max }-L_{\min }\right) & L_{\min }<L_{h}<L_{\max } \\
\mu_{M}=0 & \text { otherwise }
\end{array}
$$

As depicted in Fig. 6, the maximizing set intersects each trapezoidal fuzzy set in two places. A right utility value, $U_{R}$, can be determined on the basis of these intersection points; the value for $U_{R}$ for each fuzzy set is the largest of these two intersection values. Similarly, a minimizing set, $\mu_{G}$, is defined as:

$$
\begin{array}{ll}
\mu_{G}=\left(L_{h}-L_{\max }\right) /\left(L_{\min }-L_{\max }\right) & L_{\min }<L_{h}<L_{\max } \\
\mu_{G}=0 & \text { otherwise }
\end{array}
$$

The value for the left utility value, $U_{L}$, is the maximum of the two intersection values of the minimizing set and the 
fuzzy set. The total utility or ordering value, $U$, for each alternative is found by the following equation:

$$
U=\frac{U_{R}+1-U_{L}}{2}
$$

For the example provided here the final order of alternatives was as follows:

$$
\begin{array}{ll}
\text { 1. NTO/MMH } & \mathrm{U}=0.681 \\
\text { 2. LOX/CH4 } & \mathrm{U}=0.522 \\
\text { 3. LOX/LH2 } & \mathrm{U}=0.324
\end{array}
$$

In this example the order of selection was not clear from the original range of data. This is often the case when decisions are made on the development of new systems. However, the fuzzy logic methods provide a systematic approach to making a selection when the criteria are vague and of varying importance. In this case the NTO/MMH system had lower performance than the other options, but the combination of lower weight and lower cost led to its high ranking. Note that the results were highly sensitive to the importance factors assumed. If all the criteria were assumed to be of equal importance then the order of selection was LOX/CH4, then NTOMMMH, followed by LOX/LH2. The balancing factor, $p$, did not significantly impact the results, however. In this example only four criteria were used to compare three alternatives; this process can easily be extended to many more criteria and alternatives. This example shows the utility of fuzzy logic techniques in providing a method for decision-making when the basic evaluating criteria are uncertain.

\section{Concluding Remarks}

A study was performed to demonstrate the use of fuzzy logic approaches to assist in decision-making under conditions of vague or qualitative criteria. Such situations arise when the evaluation criteria for the best option among alternatives are of unequal importance. One approach used is based on the concept of applying a subjective value to each alternative according to each of the evaluation criteria. Weighting factors can then be applied to the raw scores to provide a final ranking for each option on the basis of the relative importance of each criteria. Two examples were provided to illustrate the fuzzy logic decision-making procedure by using this approach. Another method used criteria that were objective but uncertain. In this case ranges of values were used for factors such as cost, performance, and reliability. A final ranking of the alternatives was obtained by using weighting factors and fuzzy set theory. One example was provided to illustrate this method.
The fuzzy logic methods shown here provide powerful tools for comparing alternatives under subjective and uncertain evaluation procedures. Fuzzy logic allows for quantifying vague or qualitative ideas, which are common in multi-objective problems. Also, as in other decision-making processes presented here, the evaluating criteria or objectives are rated against each other during the process, forcing the decision maker to decide what is most important to the final result. Most importantly, the process provides a result based on the degree to which each alternative meets each objective, thereby allowing for a decision based on factors that may have been overlooked in conventional procedures. On the basis of the results in this study fuzzy logic provides an excellent framework for assisting in often-difficult process of selecting the best option among many alternatives.

\section{Acknowledgment}

The author wishes to thank Joseph Hemminger of NASA Lewis Research Center for his assistance in assembling the Space Propulsion Synergy Group information for this report.

\section{References}

1. Kosko, B., Fuzzy Thinking: The New Science of Fuzzy Logic, Hyperion, NY, 1993.

2. McNeil, D., and Freiberger, P., Fuzzy Logic, Simon and Schuster, NY, 1993.

3. Brubaker, D.I., "Fuzzy-Logic Basics: Intuitive Rules Replace Complex Math," EDN, June 18, 1992, pp. 111-116.

4. Kosko, B., and Isaka, S., "Fuzzy Logic," Scientific American, July 1993, pp. 76-81.

5. Park, K.S., "Fuzzy Apportionment of System Reliability," EEEE Trans. Rel, Vol. R-36, No. 1, Apr. 1987, p. 129-132.

6. Hardy, T.L., and Rapp, D.C., “Rocket Engine System Reliability Using Probabilistic and Fuzzy Logic Techniques," AIAA Paper 94-2750, 1994.

7. Anandalingam, G., and Westfall, M., "Selection of Hazardous Waste Disposal Alternative Using MultiAttribute Utility Theory and Fuzzy Set Analysis," Lournal of Environmental Systems, Vol. 18, No. 1, 1988, pp. 69-85.

8. Horsak, R.D., and Damico, S.A., "Selection and Evaluation of Hazardous Waste Disposal Sites Using Fuzzy Set Analysis," L. Air Pollution Control Association," Vol. 35, No. 10, Oct. 1985, pp. 1081-1085.

9. Bogardi, I., and Bardossy, A., "Regional Management of an Aquifer for Mining Under Fuzzy Environmental Objectives," Water Resources Research, Vol. 19, No. 6, 1983, pp. 1394-1402. 
10. Lee, Y.W., Bogardi, I., and Stansbury, J., "Fuzzy Decision Making in Dredged Material Management," J. Environmental Engineering, ASCE, Vol. 117, No. 5, 1991, pp. 614-631.

11. Zadeh, L., "Fuzzy Sets," Information and Control, Vol. 8, 1965, pp. 338-353.

12. Yager, R.R., "Multiple Objective Decision-Making Using Fuzzy Sets," Int. J. Man-machine Studies, Vol. 9, 1977, pp. 375-382.

13. Asker, J.R., "Radical Upgrades Urged to Cut Shuttle Costs," Aviation Week \& Space Technology, Nov. 29, 1993, pp. 42-44.

14. Dankhoff, W.F., and Hope, W.P., "Overview of the Space Propulsion Synergy Group (SPSG) Strategic Planning Efforts for Earth to Orbit Transportation," AIAA Paper 93-1851, 1993.
15. Bray, J., "Payoffs for Applying QFD Techniques in the SPSG Strategic Planning Support Effort for ETO Transportation and Propulsion Systems," AIAA Paper 93-1852, 1993.

16. Hemminger, J., NASA Lewis Research Center, personal communication, Nov., 1993.

17. Paek, J.H., Lee, Y.W., and Napier, T.R., "Selection of Design/Build Proposal Using Fuzzy Logic System," $J$. Construction Engineering and Management, Vol. 118, No. 2, June 1992, pp. 303-317.

18. Hurlbert, E., "Lunar Lander and Return Propulsion System Trade Study," NASA TP 3388, August 1993.

TABLE 1.-RAW SCORES FOR VENDOR PROPOSAL EXAMPLE.

\begin{tabular}{|c|c|c|c|c|}
\hline & \multicolumn{4}{|c|}{ Vendor } \\
\hline Evaluation criteria & A & B & C & D \\
\hline Technical Item 1 & .1 & .9 & .5 & .5 \\
\hline Technical Item 2 & .5 & .9 & .5 & .5 \\
\hline Technical Item 3 & .7 & .7 & .5 & .3 \\
\hline Technical Item 4 & .9 & .9 & .3 & .7 \\
\hline Technical Item 5 & .9 & .7 & .7 & .5 \\
\hline Cost & .3 & .5 & .7 & .5 \\
\hline
\end{tabular}

TABLE 2.-WEIGHTED SCORES FOR VENDOR PROPOSAL EXAMPLE: CONVENTIONAL METHOD.

\begin{tabular}{|c|c|c|c|c|c|}
\hline & & \multicolumn{4}{|c|}{ Vendor } \\
\hline Evaluation criteria & Weight & A & B & C & D \\
\hline Technical item 1 & .15 & .015 & .135 & .075 & .075 \\
\hline Technical item 2 & .15 & .075 & .135 & .075 & .075 \\
\hline Technical item 3 & .10 & .070 & .070 & .050 & .030 \\
\hline Technical item 4 & .05 & .045 & .045 & .015 & .035 \\
\hline Technical item 5 & .05 & .045 & .035 & .035 & .025 \\
\hline Cost & .50 & .150 & .250 & .350 & .250 \\
\hline Total score & & .400 & .670 & .600 & .490 \\
\hline
\end{tabular}

Order of selection: B, C, D, A 
TABLE 3.- PAIRED ATTRIBUTE MATRIX FOR VENDOR PROPOSAL EXAMPLE.

\begin{tabular}{|c|c|c|c|c|c|c|c|}
\hline & & & & & $\begin{array}{l}\text { ht) } \\
\text { hte }\end{array}$ & & \\
\hline & & $\begin{array}{c}1 \\
(.15)\end{array}$ & $\begin{array}{c}2 \\
(.15)\end{array}$ & $\begin{array}{c}3 \\
(.10)\end{array}$ & $\begin{array}{c}4 \\
(.05)\end{array}$ & $\begin{array}{c}5 \\
(.05)\end{array}$ & $\begin{array}{c}6 \\
(.50)\end{array}$ \\
\hline & $\begin{array}{c}1 \\
(.15)\end{array}$ & 1.00 & 1.00 & 1.50 & 3.00 & 3.00 & .30 \\
\hline & $\begin{array}{c}2 \\
(.15)\end{array}$ & 1.00 & 1.00 & 1.50 & 3.00 & 3.00 & .30 \\
\hline $\begin{array}{l}\text { Attribute } \\
\text { (weight) }\end{array}$ & $\begin{array}{c}3 \\
(.10)\end{array}$ & .67 & .67 & 1.00 & 2.00 & 2.00 & 0.20 \\
\hline & $\begin{array}{c}4 \\
(.05)\end{array}$ & .33 & .33 & .50 & 1.00 & 1.00 & .10 \\
\hline & $\begin{array}{c}5 \\
(.05)\end{array}$ & .33 & .33 & .50 & 1.00 & 1.00 & .10 \\
\hline & $\begin{array}{c}6 \\
(.50)\end{array}$ & 3.33 & 3.33 & 5.00 & 10.00 & 10.00 & 1.00 \\
\hline
\end{tabular}

where:

$$
\begin{aligned}
& \text { Attribute } 1=\text { Technical item } 1(\text { weight }=0.15) \\
& \text { Attribute } 2=\text { Technical item } 2(\text { weight }=0.15) \\
& \text { Attribute } 3=\text { Technical item } 3(\text { weight }=0.10) \\
& \text { Attribute } 4=\text { Technical item } 4(\text { weight }=0.05) \\
& \text { Attribute } 5=\text { Technical item } 5(\text { weight }=0.05) \\
& \text { Attribute } 6=\text { Cost }(\text { weight }=0.50)
\end{aligned}
$$

Resulting eigenvector: $(0.269,0.269,0.180,0.090,0.090,0.898)$

TABLE 4.-WEIGHTED SCORES FOR VENDOR PROPOSAL EXAMPLE: FUZZY LOGIC METHOD.

\begin{tabular}{|c|c|c|c|c|c|}
\hline & & \multicolumn{4}{|c|}{ Vendor } \\
\hline Evaluation criteria & Weight & $\mathrm{A}$ & $\mathrm{B}$ & $\mathrm{C}$ & $\mathrm{D}$ \\
\hline Technical item 1 & .269 & .538 & .972 & .830 & .830 \\
\hline Technical item 2 & .269 & .830 & .972 & .830 & .830 \\
\hline Technical item 3 & .180 & .938 & .938 & .883 & .805 \\
\hline Technical item 4 & .090 & .991 & .991 & .897 & .968 \\
\hline Technical item 5 & .090 & .991 & .968 & .968 & .940 \\
\hline Cost & .898 & .339 & .537 & .726 & .537 \\
\hline Minimum score & & .339 & .537 & .726 & .537 \\
\hline
\end{tabular}

Order of selection: C, B/D, A 
TABLE 5.- SPACE PROPULSION SYNERGY GROUP PROPULSION OPTIONS.

\begin{tabular}{|c|l|c|}
\hline Option Designation & \multicolumn{1}{|c|}{ Vehicle Candidate } & Access to Space Option No. \\
\hline A & Existing Expendables (Upgrade) & - \\
\hline B & Existing Reusable (STS, Upgrade) & 2 \\
\hline C & Conventional Expendable & 2 \\
\hline D & Conventional Partially Reusable & 3 \\
\hline E & SSTO O2/H2 Rocket & 3 \\
\hline F & SSTO RBCC & 3 \\
\hline G & TSTO AR Fully Reusable & 3 \\
\hline H & SSTO Dual Fuel & 3 \\
\hline I & SSTO Slush H2 RBCC & - \\
\hline
\end{tabular}

TABLE 6.- SPACE PROPULSION SYNERGY GROUP RESULTS: ALL ATTRIBUTES.

\begin{tabular}{|l|c|c|c|c|c|c|c|c|c|c|}
\hline \multicolumn{1}{|c|}{} & \multicolumn{7}{|c|}{ Vehicle Candidates } \\
\hline Attribute & Weight & A & B & C & D & E & F & G & H & I \\
\hline 1. Low recurring cost & 11.13 & 1 & 1 & 3 & 3 & 9 & 9 & 9 & 3 & 3 \\
\hline 2. Low non-recurring cost & 1.48 & 9 & 9 & 3 & 3 & 3 & 1 & 1 & 1 & 1 \\
\hline 3. Min. effect on atmosphere & 1.11 & 1 & 1 & 3 & 3 & 3 & 3 & 3 & 1 & 3 \\
\hline 4. Min. envir. impact at all sites & 1.11 & 1 & 1 & 3 & 3 & 3 & 3 & 3 & 1 & 3 \\
\hline 5. Vehicle safety & 2.32 & 1 & 1 & 3 & 3 & 9 & 9 & 9 & 3 & 3 \\
\hline 6. Personnel safety & 1.48 & 3 & 3 & 9 & 9 & 9 & 9 & 9 & 9 & 3 \\
\hline 7. Equipment/vehicle safety & 1.48 & 3 & 3 & 9 & 9 & 9 & 9 & 9 & 3 & 3 \\
\hline 8. Intact vehicle recovery & 3.09 & 0 & 1 & 0 & 1 & 3 & 9 & 9 & 3 & 3 \\
\hline 9. Mission success & 2.78 & 1 & 1 & 3 & 3 & 9 & 9 & 3 & 3 & 3 \\
\hline 10. Launch on time & 6.95 & 1 & 1 & 3 & 3 & 9 & 9 & 3 & 1 & 1 \\
\hline 11. Flexible & 3.34 & 1 & 1 & 3 & 3 & 9 & 9 & 3 & 1 & 1 \\
\hline 12. Capacity & 7.42 & 1 & 1 & 3 & 3 & 9 & 9 & 9 & 1 & 1 \\
\hline 13. Vehicle health management & 4.45 & 1 & 3 & 3 & 3 & 9 & 9 & 9 & 1 & 3 \\
\hline 14. Easy vehicle integration & 8.90 & 0 & 1 & 3 & 3 & 9 & 9 & 3 & 9 & 9 \\
\hline 15. Maintainable & 8.90 & 0 & 1 & 3 & 3 & 9 & 9 & 3 & 3 & 3 \\
\hline 16. Simple & 5.34 & 0 & 0 & 3 & 3 & 3 & 3 & 3 & 3 & 3 \\
\hline 17. Launch on demand & 5.34 & 0 & 0 & 1 & 1 & 3 & 3 & 1 & 3 & 3 \\
\hline 18. Easily supportable & 11.13 & 0 & 0 & 3 & 1 & 9 & 9 & 3 & 3 & 1 \\
\hline 19. Technology options & 1.67 & 3 & 3 & 9 & 9 & 3 & 1 & 3 & 1 & 1 \\
\hline 20. Technology readiness & 3.34 & 3 & 3 & 3 & 3 & 1 & 1 & 1 & 1 & 1 \\
\hline 21. Technology margin & 1.48 & 9 & 9 & 9 & 9 & 3 & 1 & 3 & 3 & 1 \\
\hline 22. Benefit GNP & 2.97 & 1 & 1 & 3 & 3 & 9 & 9 & 9 & 3 & 3 \\
\hline 23. Social perception & 2.78 & 1 & 1 & 3 & 3 & 9 & 9 & 9 & 9 & 9 \\
\hline \hline Weighted Scores & & 97 & 127 & 317 & 298 & 729 & 739 & 502 & 324 & 303 \\
\hline
\end{tabular}


TABLE 7.- SPACE PROPULSION SYNERGY GROUP RESULTS: TOP NINE ATTRIBUTES, CONVENTIONAL ANAL YSIS.

a) Raw values

\begin{tabular}{|l|c|c|c|c|c|c|c|c|c|}
\hline & \multicolumn{10}{|c|}{ Options } \\
\hline \multicolumn{1}{|c|}{ Attribute } & A & B & C & D & E & F & G & H & I \\
\hline 1. Low recurring cost & 1 & 1 & 3 & 3 & 9 & 9 & 9 & 3 & 3 \\
\hline 10. Launch on time & 1 & 1 & 3 & 3 & 9 & 9 & 3 & 1 & 1 \\
\hline 12. Capacity & 1 & 1 & 3 & 3 & 9 & 9 & 9 & 1 & 1 \\
\hline 13. Vehicle health management & 1 & 3 & 3 & 3 & 9 & 9 & 9 & 1 & 3 \\
\hline 14. Easy vehicle integration & 0 & 1 & 3 & 3 & 9 & 9 & 3 & 9 & 9 \\
\hline 15. Maintainable & 0 & 1 & 3 & 3 & 9 & 9 & 3 & 3 & 3 \\
\hline 16. Simple & 0 & 0 & 3 & 3 & 3 & 3 & 3 & 3 & 3 \\
\hline 17. Launch on demand & 0 & 0 & 1 & 1 & 3 & 3 & 1 & 3 & 3 \\
\hline 18. Easily supportable & 0 & 0 & 3 & 1 & 9 & 9 & 3 & 3 & 1 \\
\hline
\end{tabular}

b) Weighted values

\begin{tabular}{|l|c|c|c|c|c|c|c|c|c|c|}
\hline \multicolumn{1}{|c|}{ Attribute } & Weight & A & B & C & D & E & F & G & H & I \\
\hline 1. Low recurring cost & 11.13 & 11.1 & 11.1 & 33.4 & 33.4 & 100. & 100. & 100. & 33.4 & 33.4 \\
\hline 10. Launch on time & 6.95 & 7.0 & 7.0 & 20.9 & 20.9 & 62.6 & 62.6 & 20.9 & 7.0 & 7.0 \\
\hline 12. Capacity & 7.42 & 7.4 & 7.4 & 22.3 & 22.3 & 66.8 & 66.8 & 66.8 & 7.4 & 7.4 \\
\hline 13. Vehicle health management & 4.45 & 4.5 & 13.4 & 13.4 & 13.4 & 40.1 & 40.1 & 40.1 & 4.5 & 13.4 \\
\hline 14. Easy vehicle integration & 8.90 & 0.0 & 8.9 & 26.7 & 26.7 & 80.1 & 80.1 & 26.7 & 80.1 & 80.1 \\
\hline 15. Maintainable & 8.90 & 0.0 & 8.9 & 26.7 & 26.7 & 80.1 & 80.1 & 26.7 & 26.7 & 26.7 \\
\hline 16. Simple & 5.34 & 0.0 & 0.0 & 16.0 & 16.0 & 16.0 & 16.0 & 16.0 & 16.0 & 16.0 \\
\hline 17. Launch on demand & 5.34 & 0.0 & 0.0 & 5.3 & 5.3 & 16.0 & 16.0 & 5.3 & 16.0 & 16.0 \\
\hline 18. Easily supportable & 11.13 & 0.0 & 0.0 & 33.4 & 11.1 & 100. & 100. & 33.4 & 33.4 & 11.1 \\
\hline \hline Total & & 30. & 57. & 198. & 176. & 562. & 562. & 336. & 224. & 211. \\
\hline
\end{tabular}

Order of Selection: E/F, G, H, I, C, D, B, A 
TABLE 8.- SPACE PROPULSION SYNERGY GROUP RESULTS USING FUZZY LOGIC.

a) Raw values

\begin{tabular}{|l|c|c|c|c|c|c|c|c|c|}
\hline & \multicolumn{9}{|c|}{ Options } \\
\hline \multicolumn{1}{|c|}{ Attribute } & A & B & C & D & E & F & G & H & I \\
\hline 1. Low recurring cost & .1 & .1 & .3 & .3 & .9 & .9 & .9 & .3 & .3 \\
\hline 10. Launch on time & .1 & .1 & .3 & .3 & .9 & .9 & .3 & .1 & .1 \\
\hline 12. Capacity & .1 & .1 & .3 & .3 & .9 & .9 & .9 & .1 & .1 \\
\hline 13. Vehicle health management & .1 & .3 & .3 & .3 & .9 & .9 & .9 & .1 & .3 \\
\hline 14. Easy vehicle integration & 0 & .1 & .3 & .3 & .9 & .9 & .3 & .9 & .9 \\
\hline 15. Maintainable & 0 & .1 & .3 & .3 & .9 & .9 & .3 & .3 & .3 \\
\hline 16. Simple & 0 & 0 & .3 & .3 & .3 & .3 & .3 & .3 & .3 \\
\hline 17. Launch on demand & 0 & 0 & .1 & .1 & .3 & .3 & .1 & .3 & .3 \\
\hline 18. Easily supportable & 0 & 0 & .3 & .1 & .9 & .9 & .3 & .3 & .1 \\
\hline
\end{tabular}

b) Weighted values

\begin{tabular}{|l|c|c|c|c|c|c|c|c|c|c|}
\hline \multicolumn{1}{|c|}{ Attribute } & Weight & $\mathrm{A}$ & $\mathrm{B}$ & $\mathrm{C}$ & $\mathrm{D}$ & $\mathrm{E}$ & $\mathrm{F}$ & $\mathrm{G}$ & $\mathrm{H}$ & $\mathrm{I}$ \\
\hline 1. Low recurring cost & .46 & .35 & .35 & .57 & .57 & .95 & .95 & .95 & .57 & .57 \\
\hline 10. Launch on time & .29 & .51 & .51 & .71 & .71 & .97 & .97 & .71 & .51 & .51 \\
\hline 12. Capacity & .31 & .49 & .49 & .69 & .69 & .97 & .97 & .97 & .49 & .49 \\
\hline 13. Vehicle health management & .18 & .66 & .81 & .81 & .81 & .98 & .98 & .98 & .66 & .81 \\
\hline 14. Easy vehicle integration & .37 & 0 & .43 & .64 & .64 & .96 & .96 & .64 & .96 & .96 \\
\hline 15. Maintainable & .37 & 0 & .43 & .64 & .64 & .96 & .96 & .64 & .64 & .64 \\
\hline 16. Simple & .22 & 0 & 0 & .77 & .77 & .77 & .77 & .77 & .77 & .77 \\
\hline 17. Launch on demand & .22 & 0 & 0 & .60 & .60 & .77 & .77 & .60 & .77 & .77 \\
\hline 18. Easily supportable & .46 & 0 & 0 & .57 & .35 & .95 & .95 & .57 & .57 & .35 \\
\hline \hline Minimum & & 0 & 0 & .57 & .35 & .77 & .77 & .57 & .49 & .35 \\
\hline
\end{tabular}

Order of selection: $E / F, C / G, H, D / A, A / B$ 
TABLE 9.- BASIC CRITERION VALUES FOR UPPER STAGE ALTERNATIVES.

\begin{tabular}{|c|c|c|c|c|c|c|}
\hline \multirow{2}{*}{ Basic criteria } & \multicolumn{2}{|c|}{ LOX/LH2 } & \multicolumn{2}{c|}{ NTO/MMH } & \multicolumn{2}{c|}{ LOX/CH4 } \\
\cline { 2 - 7 } & $\begin{array}{c}\text { Largest } \\
\text { likely } \\
\text { interval }\end{array}$ & $\begin{array}{c}\text { Most } \\
\text { likely } \\
\text { interval }\end{array}$ & $\begin{array}{c}\text { Largest } \\
\text { likely } \\
\text { interval }\end{array}$ & $\begin{array}{c}\text { Most } \\
\text { likely } \\
\text { interval }\end{array}$ & $\begin{array}{c}\text { Largest } \\
\text { likely } \\
\text { interval }\end{array}$ & $\begin{array}{c}\text { Most } \\
\text { likely } \\
\text { interval }\end{array}$ \\
\hline Cost (\$M) & $3-5$ & $3.5-4.5$ & $1.5-3.5$ & $2-3$ & $2-4$ & $2.5-3.5$ \\
\hline Specific impulse (sec) & $430-450$ & $435-445$ & $310-330$ & $315-325$ & $340-360$ & $345-355$ \\
\hline Weight (kg) & $210-290$ & $230-270$ & $120-190$ & $135-165$ & $200-280$ & $220-260$ \\
\hline Reliability & $.96-.995$ & $.98-.99$ & $.96-.995$ & $.98-.99$ & $.94-.99$ & $.96-.97$ \\
\hline
\end{tabular}

TABLE 10.- BEST AND WORST VALUES FOR EACH BASIC CRITERION.

\begin{tabular}{|c|c|c|}
\hline Basic criterion & Best value & Worst value \\
\hline Cost $(\$ M)$ & 0 & 5 \\
\hline Specific impulse $(\mathrm{sec})$ & 500 & 0 \\
\hline Weight $(\mathrm{kg})$ & 0 & 300 \\
\hline Reliability & 1 & 0 \\
\hline
\end{tabular}

TABLE 11.- WEIGHTING FACTORS FOR EACH BASIC CRITERION.

\begin{tabular}{|c|c|}
\hline Criterion & Weight \\
\hline Specific impulse & .354 \\
\hline Weight & .177 \\
\hline Reliability & .467 \\
\hline Technical & .400 \\
\hline Cost & .600 \\
\hline
\end{tabular}



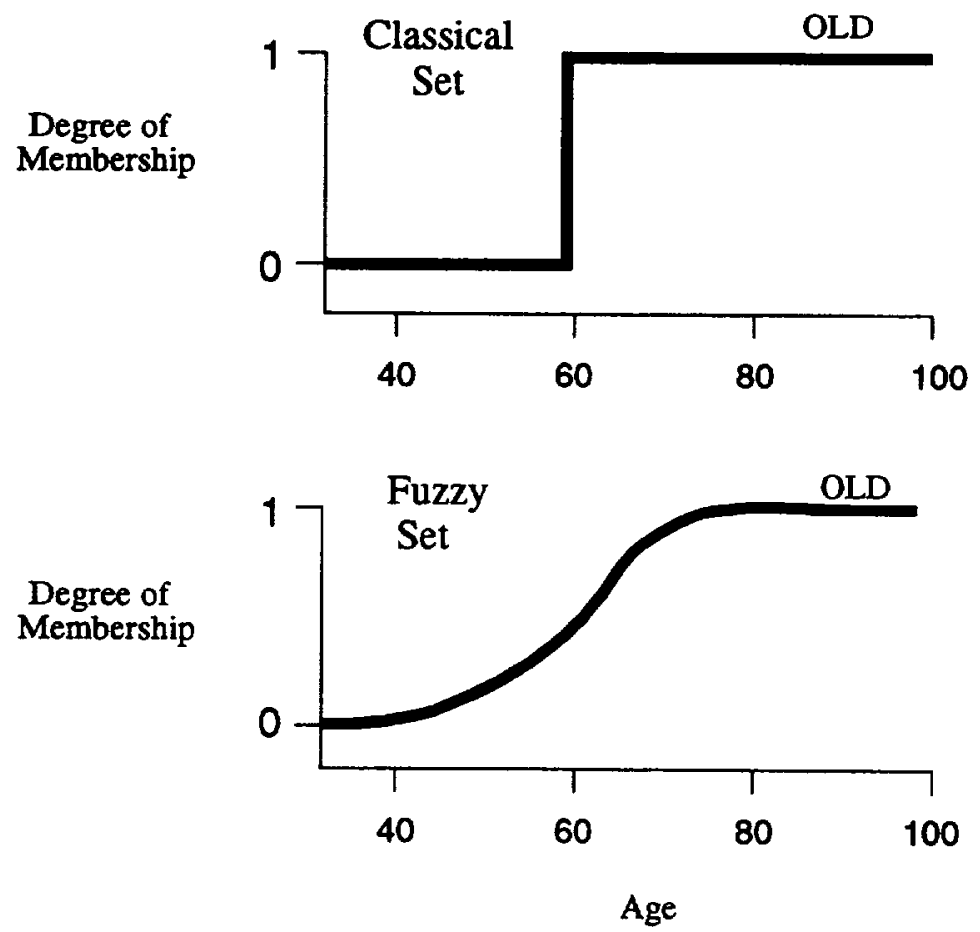

Figure 1.- Comparison of classical set with fuzzy set for the set "old".
First level
Second level
Final level

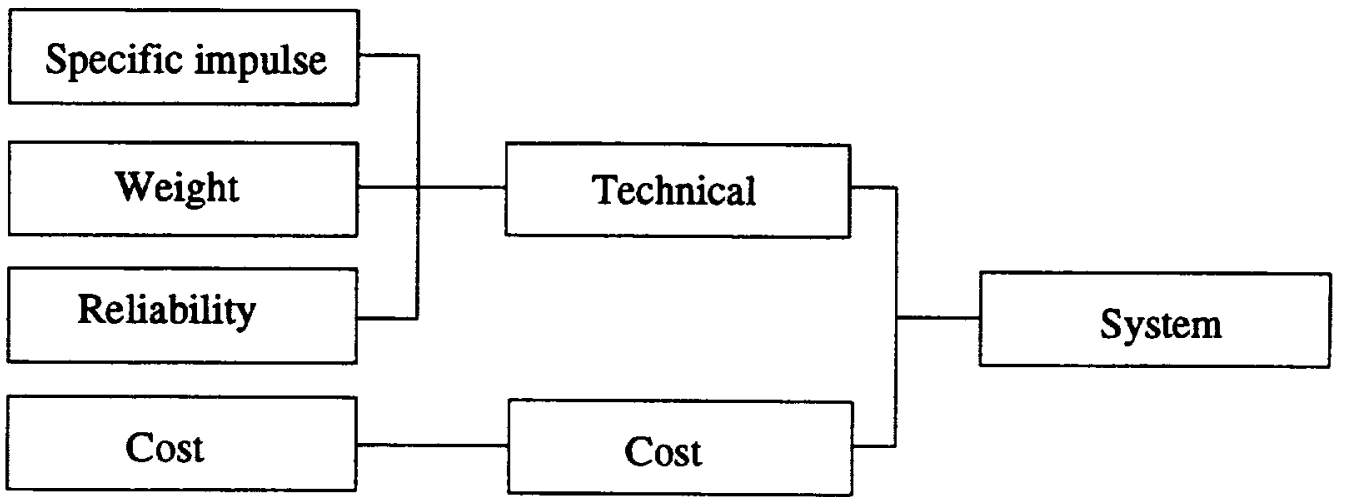

Figure 2.- Example of the composite procedure for selection of an upper stage propulsion system. 


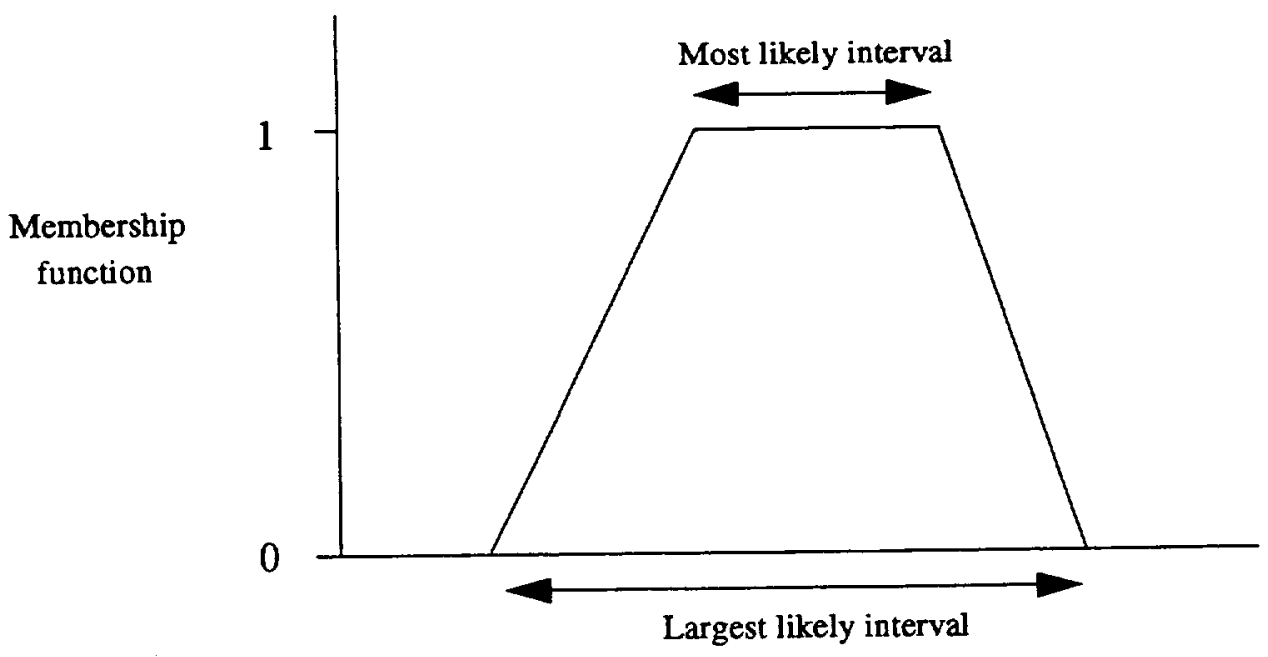

Value of criterion, $\mathrm{Z}$

Figure 3.- Fuzzy set for a basic criterion.

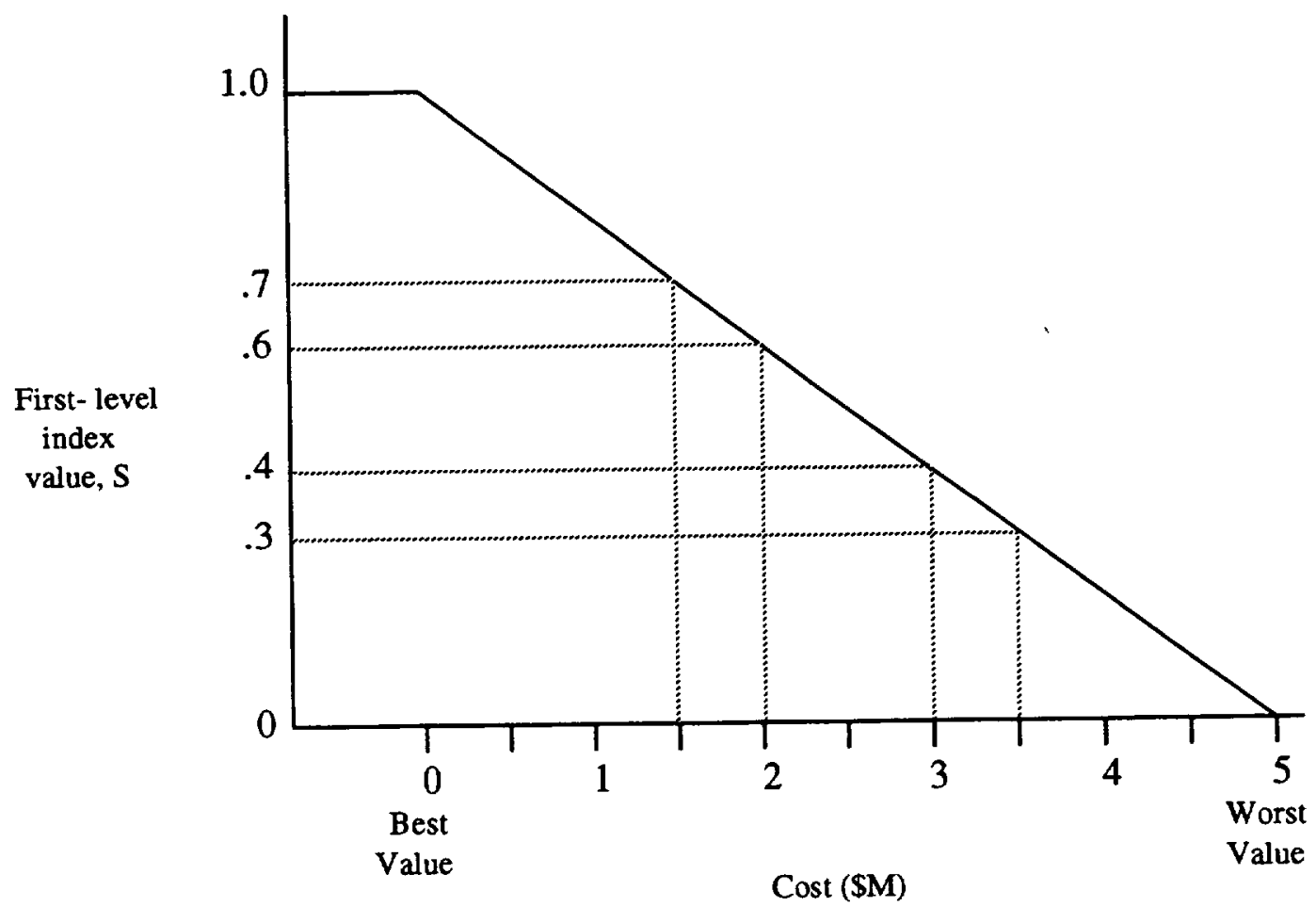

Figure 4. Example of transferring actual value to first -level index value for cost of NTO/MMH system. 


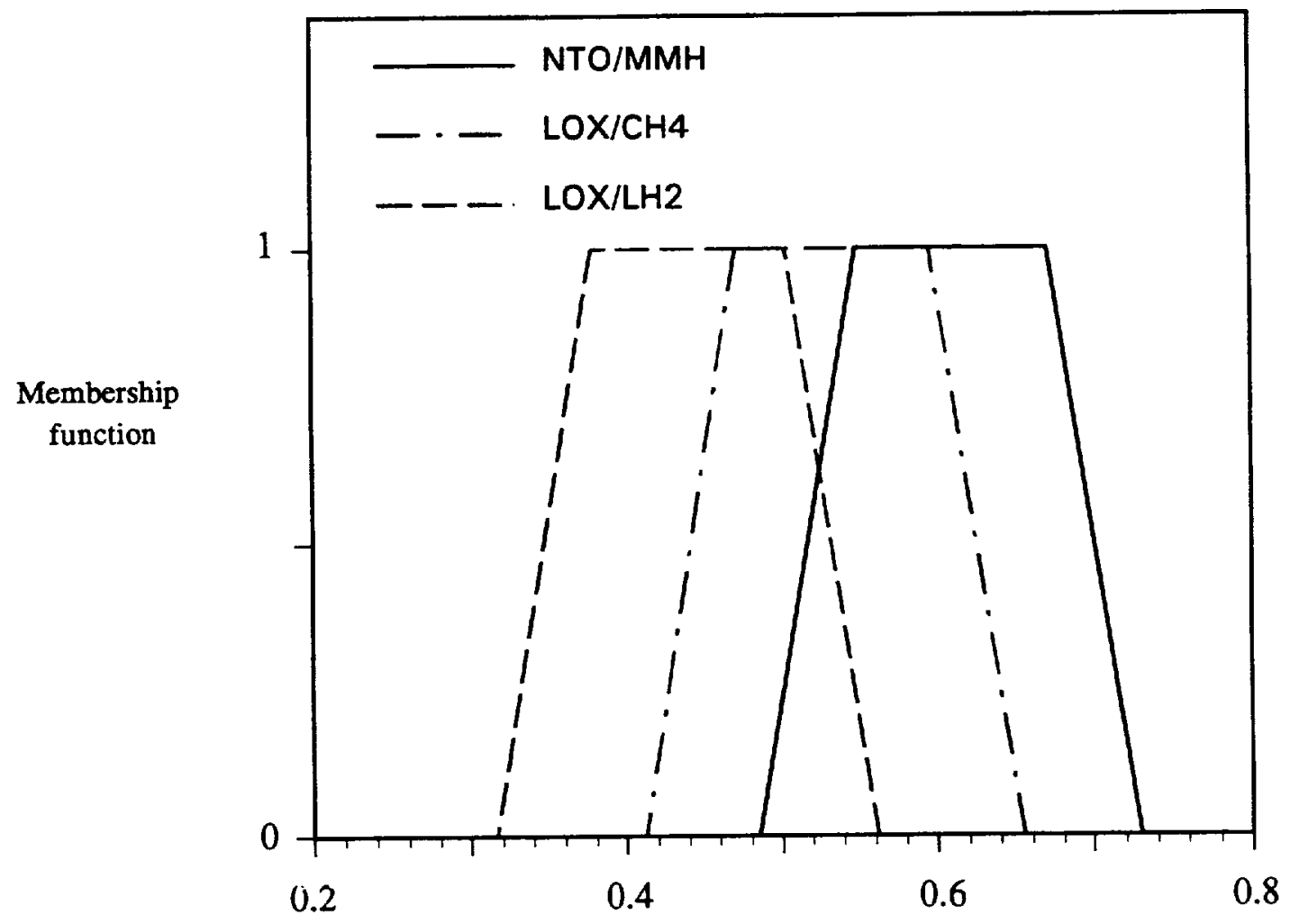

Final composite index value, $\mathrm{L}_{h}$

Figure 5.- Fuzzy sets of final composite index values for upper stage alternatives.

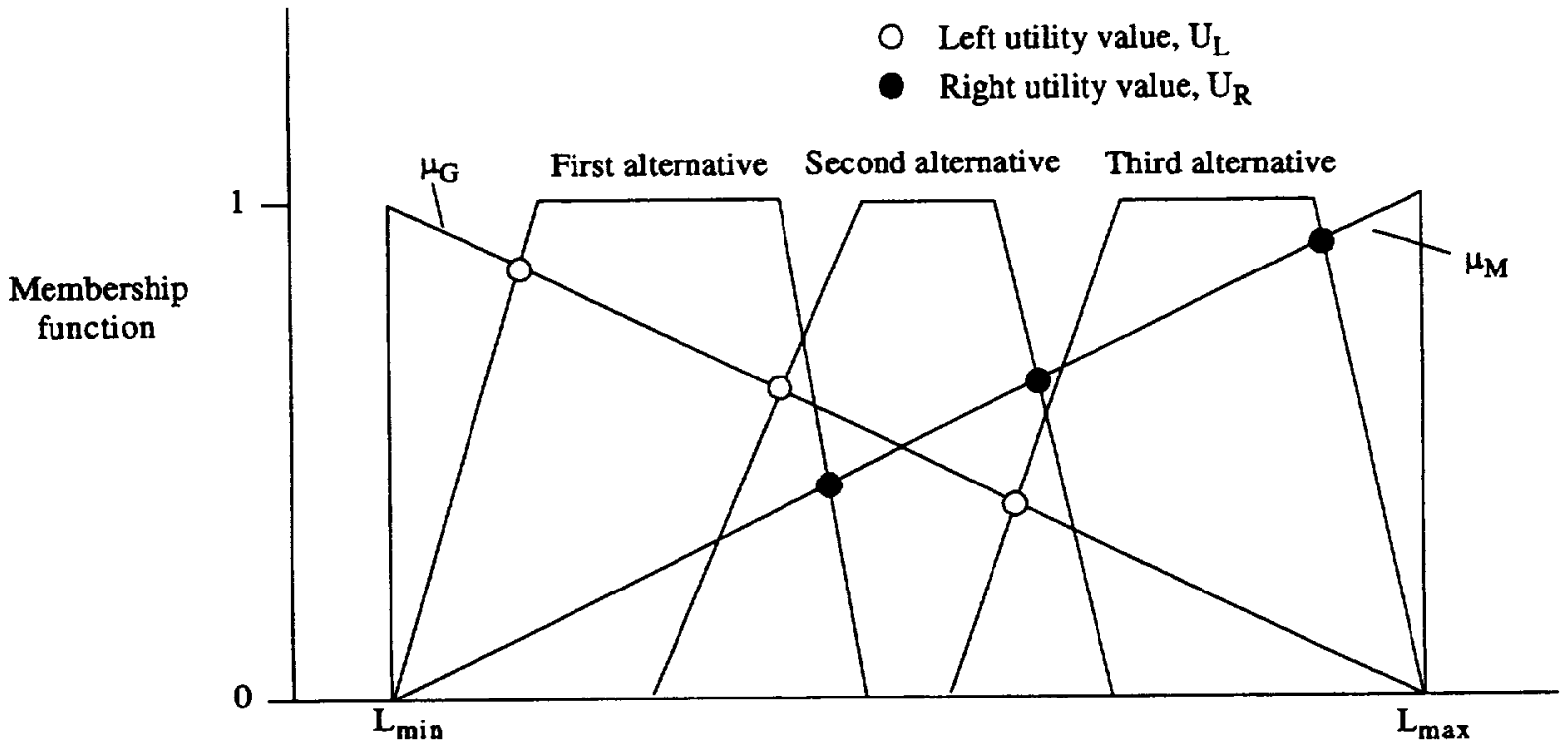

Final composite index value, $L_{h}$

Figure 6.- Ranking method of fuzzy sets. 


\begin{tabular}{|c|c|c|c|}
\hline \multicolumn{3}{|c|}{ REPORT DOCUMENTATION PAGE } & $\begin{array}{l}\text { Form Approved } \\
\text { OMB No. 0704-0188 }\end{array}$ \\
\hline \multicolumn{4}{|c|}{ 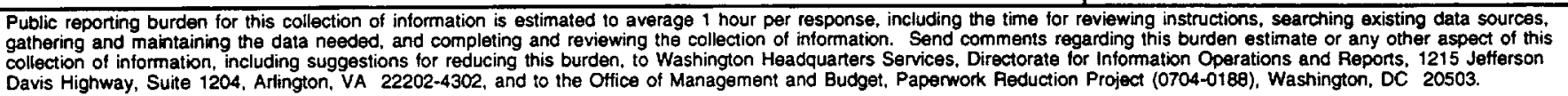 } \\
\hline 1. AGENCY USE ONLY (Leave blank) & $\begin{array}{r}\text { 2. REPORT DATE } \\
\text { June } 1994\end{array}$ & \multicolumn{2}{|c|}{$\begin{array}{l}\text { 3. REPOAT TYPE AND DATES COVERED } \\
\text { Technical Memorandum }\end{array}$} \\
\hline \multicolumn{3}{|c|}{$\begin{array}{l}\text { 4. TTLE AND SUBTITLE } \\
\text { Fuzzy Logic Approaches to Multi-Objective Decision-Making in Aerospace } \\
\text { Applications }\end{array}$} & \multirow{2}{*}{$\begin{array}{l}\text { 5. FUNDING NUMBERS } \\
\text { WU-232-02-0A }\end{array}$} \\
\hline $\begin{array}{l}\text { 6. AUTHOR(S) } \\
\text { Terry L. Hardy }\end{array}$ & 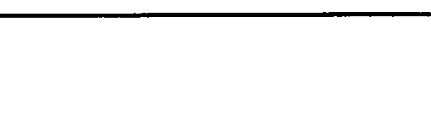 & & \\
\hline \multicolumn{3}{|c|}{$\begin{array}{l}\text { 7. PERFORMING ORGANIZATION NAME(S) AND ADDRESS(ES) } \\
\text { National Aeronautics and Space Administration } \\
\text { Lewis Research Center } \\
\text { Cleveland, Ohio } 44135-3191\end{array}$} & $\begin{array}{l}\text { 8. PERFORMING ORGANIZATION } \\
\text { REPORT NUMBER }\end{array}$ \\
\hline \multicolumn{3}{|c|}{ 9. SPONSORING/MONITORING AGENCY NAME(S) AND ADDRESS(ES) } & $\begin{array}{l}\text { 10. SPONSORINGMOMONITORING } \\
\text { AGENCY REPORT NUMBER } \\
\text { NASA TM-106599 } \\
\text { ALAA-94-3163 }\end{array}$ \\
\hline \multicolumn{4}{|c|}{$\begin{array}{l}\text { Prepared for the 30th Joint Propulsion Conference sponsored by the American Institute of Aeronautics and Astronautics, } \\
\text { Colorado, June 20-23, 1994. Responsible person, Terry L. Hardy, organization code 5320, (216) 433-7517. }\end{array}$} \\
\hline \multicolumn{3}{|c|}{$\begin{array}{l}\text { 12a. DISTRIBUTIONAVAILABILITY STATEMENT } \\
\text { Unclassified - Unlimited } \\
\text { Subject Category } 20\end{array}$} & 12b. DISTRIBUTION CODE \\
\hline \multicolumn{4}{|c|}{$\begin{array}{l}\text { Fuzzy logic allows for the quantitative representation of multi-objective decision-making problems which have vague } \\
\text { or fuzzy objectives and parameters. As such, fuzzy logic approaches are well-suited to situations where alternatives } \\
\text { must be assessed by using criteria that are subjective and of unequal importance. This paper presents an overview of } \\
\text { fuzzy logic and provides sample applications from the aerospace industry. Applications include an evaluation of vendor } \\
\text { proposals, an analysis of future space vehicle options, and the selection of a future space propulsion system. On the } \\
\text { basis of the results provided in this study, fuzzy logic provides a unique perspective on the decision-making process, } \\
\text { allowing the evaluator to assess the degree to which each option meets the evaluation criteria. Future decision-making } \\
\text { should take full advantage of fuzzy logic methods to complement existing approaches in the selection of altematives. }\end{array}$} \\
\hline \multicolumn{3}{|l|}{ 14. SUBJECT TERMS } & $\begin{array}{c}\text { 15. NUMBER OF PAGES } \\
18\end{array}$ \\
\hline \multicolumn{3}{|c|}{ Fuzzy logic; Propulsion; Aerospace; Rockets } & $\begin{array}{r}\text { 16. PRICE CODE } \\
\text { A03 }\end{array}$ \\
\hline $\begin{array}{l}\text { 17. SECURITY CLASSIFICATION } \\
\text { OF REPORT } \\
\text { Unclassified }\end{array}$ & $\begin{array}{l}\text { 18. SECURITY CLASSIFICATION } \\
\text { OF THIS PAGE } \\
\text { Unclassified }\end{array}$ & $\begin{array}{l}\text { 19. SECURITY CLASSIFICATIOI } \\
\text { OF ABSTRACT } \\
\text { Unclassified }\end{array}$ & 20. LIMITATION OF ABSTRACT \\
\hline
\end{tabular}

